\title{
El antiperonismo intelectual: de la guerra ideológica a la guerra espiritual
}

\author{
FLAVIA FIORUCCI \\ Universidad Nacional de Quilmes
}

It is not given to many to be brave and clear-sighted even at the best and most obvious moments ... In any case, intellectuals are not commonly thought of as the stuff from which heroes are made $^{1}$

\section{Introducción}

Señalar el divorcio entre la inteligencia argentina y el peronismo constituye hoy un lugar común en los debates sobre este fenómeno, tanto para condenar el carácter impopular de las clases letradas, su falta de comprensión de un acontecimiento que tendría consecuencias que no supieron advertir, como para subrayar la naturaleza represiva y antiintelectual del régimen de Perón. ${ }^{2}$ Pero más allá de dichos juicios, el antiperonismo intelectual permanece como una categoría casi inexplorada lo que se explica también por la escasez de estudios sobre el antiperonismo. Cuando en 1945 Perón surge como candidato presidencial, la intelectualidad argentina -salvo los defensores de las distintas versiones del nacionalismo local- ve en éste la confirmación de una tragedia anunciada y deposita en la figura del militar devenido político popular las peores conjeturas elaboradas a la luz de la década anterior. Perón se les aparece así cuando menos como un Franco, un Mussolini o un Hitler local. Sin embargo, poco o nada se sabe, sobre la realidad del mundo intelectual en esos años ¿Cómo los escritores expresaron su rechazo a un régimen que resumían en la frase: "Alpargatas sí, libros no?”’ ¿Cuál fue su estrategia para "sobrevivir a los

Judt (1992: 55).

2 Para una crítica de la intelectualidad antiperonista, Portantiero (1961), King (1989) y Terán (1986). Para una crítica contemporánea ver los artículos de la revista Contorno.

3 La frase proviene del líder socialista Américo Ghioldi quien en la última semana de noviembre de 1945 inició un ciclo de conferencias que tituló "Alpargatas y libros en la 
oscuros y sombríos días" del peronismo? ¿Cuál era el contenido de sus diatribas contra Perón? En síntesis: ¿en qué consistía el antiperonismo intelectual? A la luz de este vacío en los estudios sobre el peronismo en el presente capítulo se propone explorar la naturaleza y las características que asume el antiperonismo intelectual desde su conformación hasta la caída de Perón en septiembre de 1955. Para esto el trabajo realiza un breve análisis de las varias instituciones culturales y grupos por donde discurría la vida intelectual de esos años. Los puntos centrales del trabajo girarán en torno a dos argumentos. Por un lado, que ante el peronismo, la estrategia de los intelectuales es la despolitización en pos de la supervivencia; y por el otro, que la crítica cultural deviene en discurso de oposición, transformando la guerra ideológica iniciada a mediados de los treinta, en una "guerra espiritual" (entendida como la defensa de la cultura o de la vida del espíritu).

\section{El principio del consenso}

En cierta forma el antiperonismo intelectual precede al surgimiento del peronismo. La oposición a Perón por parte de los letrados deriva de las luchas antifascistas que se dieron en el país en los años treinta. La denominada "década infame" no sólo marcó en Argentina la "muerte de la República Verdadera", como denominó Tulio Harperin Donghi (1999) al clima que acompañó el fin de las primeras experiencias democráticas en ese país, sino que fue la inauguración de una etapa en donde el debate intelectual se tiñó de un internacionalismo poco antes visto. El devenir local comenzó a ser leído a través de los acontecimientos externos, principalmente europeos. El tono, el vocabulario, los mismos argumentos de la discusión política e intelectual, se cifraban al compás de lo que sucedía a miles de kilómetros. Europa vivía grandes conmociones y su eco en el país era notorio. Primero la Guerra Civil Española y luego la Segunda Guerra Mundial llevaron a la inteligencia vernácula, a un estado de "guerra ideológica" en donde se replicaba lo que sucedía en el viejo continente.

Entre los intelectuales argentinos, el liberalismo tenía desde el siglo XIX, más allá de algunas excepciones, un consenso difícilmente rebatible. Era una identidad que incluía a los socialistas y hasta algunos comunistas. Como lo resumió Carlos Altamirano (2000: 15), "el credo del progreso nacional y su

historia Argentina", como una forma de referirse a la antinomia presentada por Sarmiento entre civilización y barbarie. Según la crónica del diario La Nación, la frase fue el grito de guerra de los obreros contra los estudiantes antiperonistas de la Universidad de La Plata el 17 de octubre de 1945. 
narrativa -el relato del avance económico y civil del país, a cuya marca colaboraban los logros de la educación común- había comunicado desde comienzos de siglo a socialistas y liberales "esclarecidos, positivistas o espiritualistas." El liberalismo funcionaba como una identidad flexible y vaga pero constituía un claro generador de consenso. Las luchas y los conflictos no estaban totalmente ausentes pero éstos nunca habían significado la ruptura definitiva del campo intelectual en bandos irreconciliables. Ni siquiera el muchas veces agrio debate entre los escritores de Florida y Boedo (los primeros enrolados en una visión de la literatura "esteticista" y los segundos defensores de una literatura comprometida socialmente) reiteradamente citado por la crítica como uno de los ejes sobre los cuales los intelectuales se dividían y definían identidades dentro del campo intelectual en los veinte, terminó con el clima de cordialidad entre los intelectuales. El diálogo y la posibilidad del trabajo en equipo prevalecían. ${ }^{4}$

Sin embargo, fines de la década del veinte, el clima armónico del campo intelectual comenzó a seriamente cuestionado por el surgimiento del movimiento nacionalista local. Varios intelectuales, algunos ya reconocidos y otros que se proyectarían como importantes voces de la siguiente década, se sumaron a esta corriente. Dicha posición ideológica, resumida por uno de sus seguidores (Amadeo 1956: 112) como una "reacción antiliberal" implicaba el rechazo de la democracia liberal sobre todo de la institución parlamentaria y el sufragio popular; el rescate de la religión y los valores más tradicionales de la cultura; la adhesión a un régimen estatista y corporativista y la "necesidad de fortalecer la conciencia nacional frente al espíritu -que juzgaba extranjerizante- de la etapa precedente, pronunciándose decididamente contra la influencia de las naciones llamadas imperialistas". El nacionalismo no era sin embargo una posición monolítica y cada una de sus corrientes se decidió por reforzar y a veces por desdeñar algunos de estos puntos. A grandes rasgos y obviando una constelación de posiciones intermedias el respeto por el sufragio o su rechazo dividía la familia nacionalista en dos grandes grupos: los democráticos y los antidemocráticos. ${ }^{5}$ Pero para el liberalismo no había matices, lo que quedaba claro desde su perspectiva era la peligrosidad de esta nueva derecha.

Al mismo tiempo, el desafiante nacionalismo enarbolaba las banderas de una nueva escuela histórica -el revisionismo-que propiciaba una completa

4 De lo contrario, difícilmente se podría haber tan siquiera concebido la creación de una organización como Sociedad Argentina de Escritores en 1928. Para un resumen de las polémicas literarias, Sarlo (2003). Para una discusión sobre la desintegración del consenso liberal, Halperin Donghi (2003).

5 Para una discusión sobre el tema, Buchrucker (1987). 
revisión de la historia nacional. Éste implicaba una puesta en tela de juicio de las generaciones liberales argentinas (la de 1837 y la de 1880), las cuáles eran acusadas de extranjerizantes e impopulares. De acuerdo con los dictados del revisionismo histórico Sarmiento aparecía como un colonizado mental. Mientras, los personajes denostados por la versión liberal de la historia, los caudillos, asumían su lugar en el panteón de los grandes héroes nacionales. De esa forma, la obra del caudillo Juan Manuel de Rosas, que gobernó la provincia de Buenos Aires entre los años 1835 y 1852, se transformaba en la epopeya de la nacionalidad. Rosas era presentado como el hombre fuerte, capaz de gobernar y resistir los embates del imperialismo (había enfrentado exitosamente un bloque anglo-francés en el Río de La Plata). Los postulados del revisionismo representaban una evidente afrenta a la los letrados argentinos que se postulaban como herederos de la tradición liberal argentina.

El golpe de 1930 que puso fin al segundo gobierno de Yrigoyen en manos de un militar con obvias inclinaciones de derecha (Uriburu) dio a los nacionalistas (al menos ideológicamente) la relevancia que tanto buscaban. ${ }^{6}$ Pero cambios políticos y conflictos internos terminaron rápido con el protagonismo nacionalista. ${ }^{7}$ En 1932, al producirse un nuevo cambio de gobierno ya habían sido desplazados. Aunque breve, el protagonismo de los nacionalistas alimentó los temores de los defensores de la democracia. Pese a esto, el campo intelectual no fue quebrado totalmente, lo que se explicaba por las "ambigüedades propias del ambiente intelectual y político de este periodo" (Dolkart: 1999). La colaboración entre intelectuales nacionalistas y liberales era aún posible. Así por ejemplo Victoria Ocampo (una acérrima defensora del liberalismo) todavía abría a principios de los treinta las puertas de su casa y de la revista que dirigía (Sur) a destacados nacionalistas como los hermanos Irazusta (Rodolfo y Julio), Ernesto Palacio y Ramón Doll (Irazusta: 1975). El diario liberal La Nación continuaba publicando a un escritor de un nacionalismo militarista como Leopoldo Lugones. El ejemplo más claro que la colaboración todavía era posible fue la participación de escritores de posiciones políticas tan disímiles como Jorge Luis Borges (alguien que en 1928 había abrazado la candidatura de Yrigoyen), Roberto Giusti (miembro del Partido Socialista Independiente) y Samuel Glusberg (simpatizante de Trotsky); con Lugones en la recientemente fundada Sociedad Argentina de Escritores (1928). ${ }^{8}$ Pero el

6 Contados fueron, sin embargo, los nacionalistas que participaron directamente en este gobierno. Entre ellos se destacan Carlos Ibarguren que fue nombrado interventor de la provincia de Córdoba, mientras que Leopoldo Lugones se convirtió en algo así como un "escriba" del nuevo gobierno.

7 Ver Dolkart (1999).

8 Ver “SADE: El acta de su fundación”, Mundo Literario, 1996, 1: 8. 
inicio de la guerra civil española, en 1936, terminó con la posibilidad de cooperación entre los distintos grupos.

El conflicto español significó la polarización definitiva de la intelectualidad local. ${ }^{9}$ Desde entonces, la división en dos frentes "irreconciliables" se volvió evidente. El mundo de los letrados locales se separaba así entre "fascistas y democráticos", según apoyaran a Franco o a los Republicanos españoles. La inteligencia liberal junto con la izquierda (más o menos cercana al liberalismo) expresó sus preferencias por la República, mientras que los nacionalistas se inclinaron en su conjunto por Franco. En el campo intelectual esto significaba que las distintas tribunas (revistas, agrupaciones, tertulias), se convertían en portavoces exclusivos de uno u otro bando. Así por ejemplo la mencionada revista Sur, "voz" del establishment literario, dejó de aceptar colaboraciones de nacionalistas. ${ }^{10}$ No sin cierto tono de nostalgia el historiador de dicha corriente Julio Irazusta (1975: 227) señaló que “debido a la guerra europea, que confundió a los espíritus y los dividió en banderías irreconciliables", Victoria Ocampo le cerró sus puertas. El aislamiento de los nacionalistas reveló su lado más trágico en el suicidio de Leopoldo Lugones (1938). El que por entonces era el poeta nacional por excelencia, era acusado en una necrológica publicada en la revista Nosotros de "traicionar a la inteligencia" por haber abrazado el fascismo. ${ }^{11}$ Las etiquetas, demasiado simplistas por cierto, provenían de la posición que era hegemónica entre los intelectuales: la democrática. Desde esta perspectiva, de un lado estaban los nacionalistas, los antidemocráticos, y del otro los democráticos. Si bien, como se dijo, muchos de los nacionalistas estaban en verdad contra la democracia, no era ésta la posición de la totalidad de este movimiento, como era el caso del grupo radical de tradición Yrigoyenista FORJA, que reunía entre sus figuras más notables a Arturo Jauretche y a Raúl Scalabrini Ortiz.

Sin embargo, era claro que si la disputa española adquiría tamaño impacto era porque ésta se conjugaba en un ambiente local enraizado por el fraude, por prácticas autoritarias y un contexto de gran agitación social. Cuando en 1939 estalló la segunda guerra mundial el país hacía casi una década que era administrado por gobiernos conservadores que habían llegado al poder a través del fraude electoral. Pero a pesar de este componente antidemocrático, ninguno de

9 Uno de las primeras manifestaciones de los conflictos que iban a dividir al campo intelectual se produjó en las reuniones del Congreso de los P.E.N Club, realizado en Buenos Aires en septiembre de 1936. Guisti (1980).

10 En Sur se congregaban para ese entonces las más importantes voces de la literatura nacional. Entre otros formaban parte de ésta, Jorge Luis Borges, Adolfo Bioy Casares, Manuel Mújica Laínez y Silvina Ocampo. Para un estudio de Sur, King (1989).

11 Larra (1982: 94). 
los dos presidentes que debían su elección al fraude (el general Agustín Justo 1932-1938 y luego Roberto M. Ortiz 1938-1942), habían sido seducidos por el fascismo. Lo que no fue suficiente -vale recalcar-para convencer a los intelectuales de que el país estaba a salvo de la amenaza nazi. Si las luchas en la península ibérica habían sido decisivas para dividir el campo intelectual, el nuevo conflicto mundial iba a "caldear aún más los ánimos". Nuevamente las lealtades fueron claras, gran parte del nacionalismo apoyó a los países del Eje y los "autodenominados democráticos" se inclinaron en su totalidad por los Aliados. El tema candente fue la neutralidad sostenida por el gobierno, que aunque algunos nacionalistas (especialmente miembros de FORJA como Raúl Scalabrini Ortiz) se empeñaron en describirla como parte de la tradición histórica del país, fue leída por los liberales como un tácito apoyo al ejército nazi y como la evidencia de que el fascismo era un problema local. En 1940, el ascenso como presidente (debido a la enfermedad de Ortiz) del vicepresidente Castillo, un civil con "más amigos" en el frente nacionalista alimentó aún más aquellos temores.

No es éste el lugar para debatir sobre la verosimilitud de las hipótesis tremendistas que animaron el debate intelectual de aquella época, en donde la "infiltración nazi-fascista", se convirtió en la cuestión del momento, pero lo que es evidente es que a la luz de esta amenaza, la sociedad argentina observó una suerte de florecimiento de su sociedad civil. ${ }^{12}$ Las preocupaciones dieron origen a un gran número de instituciones y grupos en defensa de la democracia que agruparon a intelectuales y políticos de todas las tendencias. En 1935 se fundó - originada en el seno del Partido Comunista- la AIAPE (Agrupación de Intelectuales Artistas, Periodistas y Escritores), que más allá de los vaivenes de una organización que tuvo que ajustarse a exigencias partidarias, constituyó entre 1935 y 1943 un activo frente antifascista. ${ }^{13}$ El 6 de junio de 1940, luego del bombardeo alemán a Francia, se formó otro enérgico grupo antifascista que congregó a figuras (tanto políticas como intelectuales) de todo el espectro ideológico: Acción Argentina. ${ }^{14}$ Este grupo intentaba convertirse en un espacio de debate y de lucha, ajeno a identidades partidarias, en defensa de la liber-

12 La Infitración Nazi-fascista era el título de un libro publicado por el dirigente socialista Enrique Dickmann, en donde proveía evidencia detallada sobre los intentos alemanes de infiltrarse en Argentina a través de los nacionalistas. Dickmann (1939). La supuesta amenaza nazi ya ha sido desmitificada por el historiador Ronald Newton, quien la asocia a una maniobra de propaganda del Departamento de estado norteamericano. Newton (1992).

13 Para una lectura sobre la AIAPE (1997).

14 Acción Argentina fue transformándose con el tiempo hasta convertirse en un frente electoral que mucho tuvo que ver con la formación de la Unión Democrática, Bottos (2000). 
tad contra los embates del fascismo local. Europa era para los fundadores de la institución un espejo para mirar la situación local. La caída de Francia era dramática pero más trágica era la certidumbre de que el fascismo se estaba apoderando del país y que Alemania tenía pretensiones sobre Argentina. El manifiesto fundacional expresa con vehemencia el tipo de preocupaciones que animaban a estos hombres:

Hoy debemos enfrentarnos por primera vez desde que se consolidó la Independencia, con la posibilidad de que nuestra soberanía pueda ser menoscabada por la codicia extranjera. Ante esa perspectiva sería antipático y suicida no declinar ideas y sentimientos individuales para estrechar filas en un movimiento de defensa, sin otra enseña que la Argentina. ${ }^{15}$

En junio de 1943 cuando la victoria aliada parecía asegurada, un golpe de estado terminó con el gobierno de Castillo. En un principio, el golpe alimentó las esperanzas de los sectores civiles, pero la nueva administración pronto se reveló aún más autoritaria y pro-Eje que la anterior. Esta llevó adelante una política sistemática de censura y represión que intentaba desmantelar los últimos vestigios del orden liberal en pie. La sociedad civil sufrió un grave retroceso, además de los partidos políticos, la AIAPE y Acción Argentina fueron disueltas mientras que varias figuras del ambiente intelectual fueron perseguidas, encarceladas, exoneradas de sus puestos en la universidad o se vieron forzadas a exiliarse; a su vez que el nacionalismo conquistó espacios. ${ }^{16}$ Fue del seno de este gobierno que salió Juan Domingo Perón. Este coronel, miembro de un grupo de oficiales con inclinaciones nacionalistas (GOU) y admirador de Mussolini, registrando un ascenso meteórico, acumulaba en julio de 1944 los puestos de Secretario del Departamento Nacional de Trabajo (luego Secretaría de Trabajo y Previsión), Ministro de Guerra, y Vicepresidente de la nación.

Los hechos que llevaron a dicho militar a la presidencia de la nación por el voto popular son conocidos. Perón usó su puesto en la Secretaría de Trabajo para armarse del apoyo de los sindicatos. Su poder creciente alimentó recelos

15 Cf. Bottos (2000).

16 Varias figuras nacionalistas asumieron puestos claves como el escritor Gustavo Martinez Zuviría que fue nombrado ministro de Justicia e Instrucción Pública, el conocido teórico clerical Tomás Casares asumió como interventor de la Universidad de Buenos Aires y el ensayista católico Mario Amadeo se convirtió en jefe de asuntos públicos del ministerio de Relaciones Exteriores. Una de las grandes conquistas de los nacionalistas de esta época fue la introducción de la enseñanza católica en las escuelas. La victoria nacionalista fue otra vez corta, en el momento en que Argentina declaró la guerra al eje los nacionalistas fueron desplazados de sus puestos. Sin embargo esto no logró convencer a los sectores democráticos de que el nacionalismo no era tan "peligroso" como creían. 
tanto en la sociedad en su conjunto como en el ejército. Pronto el clima ideológico dejó de ser favorable a los militares del GOU. El triunfo aliado dio bríos a la oposición democrática que en septiembre de 1945 reveló todas sus fuerzas en una multitudinaria marcha "Por la libertad y la Constitución." A principios de octubre, desde el ejército se intentó desplazar a Perón de la escena política. Pero la maniobra enfrentó la movilización obrera que se congregó en la plaza de Mayo pidiendo por la libertad de su nuevo líder. Perón retornó así al centro del poder, pero ahora como candidato presidencial de las elecciones llevadas a cabo en febrero de 1946.

\section{La profecía cumplida}

Si bien es cierto que no se puede interpretar la década anterior a 1945 como un proceso histórico que derivó en el indefectible ascenso de Perón, es evidente que ésta iba a condicionar la lectura del peronismo. Perón era para los intelectuales locales la amenaza hecha realidad. A los ojos de una intelectualidad que hacía una década que venía advirtiendo sobre el peligro fascista, el coronel político no era más que la profecía cumplida. Los intelectuales "autoproclamados democráticos" difícilmente iban a olvidar el origen de Perón, es decir su vinculación con el gobierno pro-Eje inaugurado en junio de 1943. En palabras de la escritora María Rosa Oliver: "Perón había estado de agregado militar en Italia, el grupo de los coroneles, el GOU, era germanófilo, conocíamos la mentalidad castrense, entonces dijimos, bueno, ahora lo vamos a tener aquí." (Oliver: 1971). El hecho de que varios de los nacionalistas expresaran sus preferencias por Perón, confirmaba aún más el "nazifascismo" de este candidato. ${ }^{17}$ Ser antiperonista era entonces para los mayoría de los intelectuales una posición natural, un derivado lógico de las posiciones que habían tomado en los años previos.

El periodo que va entre la candidatura de Perón y su elección como presidente (de octubre de 1945 a febrero de 1946), estuvo marcado dentro del campo intelectual (para entonces declaradamente antiperonista) por un clima que oscilaba entre el pesimismo más dramático hasta el optimismo más festivo. Era claro que ninguna de las dos posiciones estaba del todo injustificada. La unión de casi todas las fuerzas políticas (los Radicales, los Demócratas

17 Así como el nacionalismo estaba dividido ideológicamente, también lo estuvo su postura frente a Perón. Mientras que el nacionalismo más elitista tuvo ciertas reticencias a apoyar a la candidatura de Perón, su vertiente populista expresó en masa su adhesión a dicha candidatura. Para una discusión sobre el tema ver Walter (1993: 99-118). 
Progresistas, los Socialistas, parte de los Conservadores y los Comunistas) en un frente electoral contra Perón (la Unión Democrática), podía explicar los buenos augurios. Una carta que el escritor Julio Cortázar le envía a uno de sus amigos, 15 días antes de las elecciones, da cuenta de lo señalado:

Por aquí las cosas siguen que arden. Tengo la leve impresión de que va a ocurrir algo grande antes del 24 de febrero. He pulsado todo lo posible el ambiente, y me he mezclado bastante en el proceloso mar de la política (que le dicen). Estuve en la proclamación de la lista comunista en el Luna Park, estuve en la del PS. Y finalmente, ayer tuve el inmenso orgullo de estar en la avenida 9 de Julio cuando la proclamación de la formula democrática. Presumo que ya habrá visto las fotos de los diarios de lo que fue aquello. Resulta imposible, absolutamente imposible intentar una descripción. Es la multitud más fabulosa que haya yo contemplado en mi vida. Si después de esto el Coronel retirado tiene todavía alguna esperanza de ganar elecciones correctas... evidentemente le funciona mal el piso alto. ${ }^{18}$

Como advirtió también otro escritor-Aldolfo Bioy Casares- en el mundo de los escritores "los peronistas" no eran una presencia visible (Sorrentino 1992). Pero frente a las señales que vislumbran una victoria se barajaban también las hipótesis más agoreras frente al poder del fascismo, que aunque ya derrotado en la guerra, continuaba en los ojos de los intelectuales argentinos más fuerte que nunca. En el número de la revista Sur dedicado al fin de la guerra, el escritor comunista Enrique Amorín se preguntaba si se había "agotado la posibilidad de ver resurgir el nazismo." Y con resignación respondía que no, que "sin campos, sin alambrados, la ideología [nazi reverdecía] por las tierras". ${ }^{19}$

La alusión al fascismo de Perón y la defensa de la democracia se articuló como uno de los ejes centrales sobre los que la Unión Democrática centró su campaña en 1946. Para muchos, este hecho fue uno de los motivos de su derrota. ${ }^{20}$ Frente al contenido social del discurso de Perón, la defensa de la libertad aparecía vacua para grandes sectores de la sociedad, que tenían preocupaciones menos abstractas que el denominado "naziperonismo". ${ }^{21}$ La adhesión de la mayoría de los letrados al antiperonismo fue expresada por éstos en una carta pública, fechada justo antes de las elecciones. En ésta describían los comicios como una opción "entre una tendencia que proscribe y escarnece la libertad de

18 Julio Cortázar, carta a Sergio Sergi 10 de febrero de 1946, en: Bernández (ed.) (2000: 197).

19 Amorín (1945: 72).

20 Para una observación de los mismos miembros de la Unión Democrática en este sentido ver el comunicado del Comité de la Sección 16 de la Unión Cívica Radical citado por Torre (1990).

21 De esta forma fue denominado por el dirigente del partido comunista Vittorio Codovilla en una serie de conferencias que dieron título a su libro Batir el naziperonismo (1946). 
expresión y de pensamiento y otra que la hace posible". ${ }^{22}$ Finalmente, realizado el recuento de votos, los intelectuales se convencieron de que el fascismo no había muerto y que había resurgido con caracteres locales en la Argentina.

\section{Perón en el poder}

El antiperonismo ocupó desde 1946 el lugar que la identidad antifascista tenía en el debate intelectual argentino desde el inicio de la Guerra Civil española. El rechazo a Perón se constituyó en un factor de aglutinación aún más fuerte que la vieja identidad, reforzando la ya existente unión en un mismo "bando" de intelectuales de distintas corrientes políticas e ideológicas. Perón -sin quererlo seguramente- infundió en el "campo intelectual democrático" un sentimiento de comunidad, una cohesión, que aunque exenta de proyectos comunes no volvería a repetirse en los años venideros. El interrogante que nos debemos preguntar a esta altura del relato es ¿por dónde discurrieron los límites de la oposición intelectual una vez que Perón asumió el poder? ¿Cuál es la reacción de la intelectualidad democrática unida en el rechazo a Perón? Si el peronismo era la amenaza de una década hecha realidad, los intelectuales no expresaron sorpresa frente al hecho consumado. Lo que sí debe ser advertido es que el triunfo de Perón no fue recibido ni con grandes declaraciones ni manifiestos. Por el contrario, el peronismo llegó para desacelerar la marcada politización del campo intelectual de los años anteriores. La revista Sur, por ejemplo, que había dedicado su número entero de julio de 1945 al avance del fascismo y al problema de la democracia de masas (ahora más pertinente con el ascenso de Perón), sólo menciona al nuevo gobierno por primera vez en agosto de 1946. Sur reprodujo el discurso que Jorge Luis Borges pronunció en la cena de desagravio que los escritores le hicieron porque el gobierno de Perón lo trasladó de su cargo en una biblioteca municipal a inspector de aves del mercado municipal. Según cuenta el escritor lo que capturó su atención fue un cartel con la leyenda "DELE DELE":

Tendré que renunciar repetí, pero mi destino personal me importa menos que ese cartel simbólico. No sé hasta donde el episodio que he referido es una parábola. Sospecho, sin embargo que la memoria y el olvido son dioses que saben bien lo que hacen. Si se han extraviado lo demás y si retienen esa absurda leyenda alguna justi-

22 "Declaración de Escritores en Apoyo a la Unión Democrática", incluida en Altamirano (2001: 183). Entre otros firman: Leónidas Barletta, Jorge Luis Borges, Raúl González Tuñón, Eduardo Mallea y Victoria Ocampo. 
ficación los asiste. Lo formulo así: las dictaduras fomentan la opresión, las dictaduras fomentan el servilismo, las dictaduras fomentan la crueldad, más abominable es el hecho de que fomenten la idiotez. Botones que balbucean imperativos, efigies de caudillos, vivas y mueras prefijados, muros exornados de nombres, ceremonias unánimes, la mera disciplina usurpando el lugar de la lucidez. ${ }^{23}$

Las declaraciones de Borges fueron proféticas sobre la forma en que Sur interpretó el peronismo: como un gobierno autoritario pero también como una manifestación de la decadencia cultural por la que atravesaba el país. El discurso citado fue la única vez en casi diez años en que Sur se refirió al peronismo directamente. A partir de 1946, Perón y sus políticas se convirtieron en un tema innombrable en las páginas de Sur que la revista sólo abordó a través de referencias cruzadas y el uso de un lenguaje en clave.

En la Sociedad Argentina de Escritores - algo así como el sindicato de los escritores-se dio una situación que se ajustaba a un patrón que llegó con Perón para quedarse: la despolitización del campo intelectual. La sociedad de los escritores, aunque concebida en sus orígenes como un gremio apolítico, al comenzar la década de los cuarenta ya había dirimido posiciones y había abandonando completamente sus pretensiones de crear una asociación profesional ajena a la guerra ideológica en que la sociedad estaba sumida. Éste no había sido un camino sin obstáculos. La apoliticidad de la asociación había sido presentada por varios de sus fundadores como uno de sus más caros principios. Era dicha característica la que iba permitir a la SADE la defensa de los intereses sectoriales. El argumento implicaba por otro lado la defensa de la autonomía del mundo literario frente a los vaivenes de la política. El fin de dicho proyecto se hace evidente cuando el ex director del suplemento cultural del diario La Nación, el escritor Arturo Cancela, decide en 1945 separarse de SADE y fundar junto con otros escritores una "contra-SADE nacionalista": ADEA, (luego peronista). Cancela decide tomar este curso de acción porque para ese entonces la política reinaba incontestable en SADE y esto se traducía en su propia marginación y la de sus compañeros ideológicos. La sociedad de los escritores se había convertido en la voz de los autodenominados democráticos en su cruzada contra el nacionalismo y sus defensores. Cuando Perón comienza a descollar en la escena política, el antinacionalismo incubado en la institución desde mediados de los treinta devino rápidamente en antiperonismo. La identificación de la SADE con el antiperonismo era por lo tanto predecible. Sin embargo, si en 1945 la asociación estaba comprometida en una lucha abierta por la defensa de la democracia, que presentaba como el único sistema

23 Borges (1946). 
en donde los escritores podían desarrollar su obra, sorprende comprobar que frente a la candidatura de Perón la asociación decide no participar en la Unión Democrática, alegando que el estatuto prohíbe las actividades políticas. ${ }^{24} \mathrm{Se}$ podría argumentar que lo que la asociación no quiere hacer es formar parte de un frente electoral, pero las actividades posteriores de la institución permiten vislumbrar que detrás de la advertencia hay una estrategia clara: la supervivencia institucional.

Durante este tiempo lo que sobresale, sobretodo si se lo contrasta con la militancia de la institución en los años anteriores, es el silencio. La institución se abstiene de expresarse sobre la marcha del 17 de octubre, sobre la amenaza "naziperonista" y sobre el resultado de las elecciones de febrero de 1946. A partir de entonces y hasta mediados de 1954, el retiro del gremio de los escritores de la vida política se hizo evidente en la ausencia de pronunciamientos públicos que se ocuparan del devenir político del país y en el deliberado silencio sobre temas políticos en las reuniones, según lo atestiguan las actas de la institución..$^{25}$ El retraimiento de la SADE significaba el abandono del compromiso que la asociación había asumido con la defensa de las libertades. Si el peronismo era una variación local del "nazismo", como lo había calificado Jorge Luis Borges en 1946, en uno de los pocos encuentros en donde un miembro de la asociación se refirió directamente al naciente peronismo, la falta de una condena pública al régimen era una clara claudicación. Sin embargo, dicha "claudicación" permitía a la SADE garantizar su supervivencia institucional, lo que implicaba que ésta continuaba siendo un árbitro de la cultura del país, ámbito en donde el gobierno tenía escasa autoridad y legitimidad. Aún si una posición más combativa podría considerarse como la conducta "ideal", era claro que con ésta la SADE no iba a llegar demasiado lejos. La exoneración de la Universidad de Buenos Aires de 423 profesores y la renuncia de otros 825 considerados antiperonistas entre 1943 y 1946, era un dato de la realidad que los miembros de SADE no podían ignorar, no sólo porque involucraba personalmente a muchos de ellos sino porque hablaba a las claras del carácter opresivo del nuevo régimen. Pero esto mismo también implicaba que ahora la vida

24 El Manifiesto del Tercer Congreso reza lo siguiente: El escritor sólo puede desarrollar su función, realizar su obra y ser fiel a su propio destino en un orden fundado en el libre consentimiento del individuo y no en cualquier sistema que restrinja o suprima la libertad... La condena de los regímenes de fuerza que este congreso sanciona, obliga a los escritores a combatir por la libertad en que radica el honor de su función social, la dignidad de su oficio y la honestidad del magisterio que ejercen. Sociedad Argentina de Escritores (1941: 50).

25 Se registraron algunos manifiestos pero éstos eran de otra naturaleza, no era la política en sentido abstracto la que motivaba la participación de la SADE sino ataques concretos contra el mundo de los letrados. Fiorucci (2001) 
intelectual debía desarrollarse en ámbitos externos al estado. Se daba algo así como una "privatización de la cultura" y la supervivencia de instituciones como la SADE cobraba una importancia vital. ${ }^{26}$

El alejamiento de la vida intelectual y cultural de la tutela del estado significó que los intelectuales se aglutinaron en otros ámbitos, como señaló Federico Neiburg, el gobierno "cohesionó a los excluidos en torno de otras actividades y de otras instituciones" (1998: 168). El Colegio Libre de Estudios Superiores (CLES), una especie de universidad informal, llamó a sus filas a incorporarse a todos los profesores exonerados y desde allí siguió proveyendo un espacio de debate para las discusiones de tipo más académico, al punto de convertirse en algo así como una shadow university hasta que sufrió la represión severa del régimen. Pero en éste también fue evidente la despolitización de las polémicas que tenían lugar en su seno y nuevamente la razón parecía explicarse por la voluntad de preservar la vida del espíritu. Como lo señaló Neiburg, en el CLES "la discusión de los proyectos para el país con la participación de políticos, empresarios y juristas en actos de verdadero contenido político, dio paso a otro tipo de actividades que tenían la triple finalidad de mantener vivas las relaciones entre los socios y amigos, proporcionarles alternativas laborales y continuar realizando un trabajo de proselitismo y de reclutamiento entre un público más amplio" (1998: 171).

Lo paradójico aquí es observar que esa "privatización" de los ámbitos letrados y académicos produjo indirectamente un boom (aunque de alguna forma artificial) de la vida intelectual. Un número nada desdeñable de revistas se fundaron en esos años, revelando la red de relaciones que se tejieron al compás de la posición antiperonista. Por un lado, la mera oposición bastaba para unir a intelectuales con posiciones diferentes y por el otro parecía que lo único que servía contra la "barbarie peronista" era oponer la alta cultura. Así surgieron revistas culturales como: Expresión (1946-1948); Realidad (19471949); Liberalis (1949-1961) e Imago Mundi (1953-1955) y desde una perspectiva bastante distinta Contorno (1953-1959). Si bien en cada una de ellas, primaban ciertos intelectuales, Expresión por ejemplo constituía una publicación de izquierda mientras que Realidad estaba dominada por un marcado antimarxismo, los nombres se repetían en unas y otras y las diferencias ideológicas no importaban demasiado, así por ejemplo Giusti estaba tanto en Expresión como en Liberalis. Pero lo que también resulta notorio es que salvo Libe-

26 Silvia Sigal señala esto como una constante del campo intelectual argentino. La vulnerabilidad de la universidad (estrechamente correlacionada en el país a los vaivenes de la política), favoreció el desarrollo de "instituciones" autónomas como el CLES y el Instituto Di Tella más tarde y consolidó lo que la historiadora llama la capacidad de autoorganización de los intelectuales. Sigal (1996: 100-103). 
ralis ninguna de las nuevas publicaciones logró sobrevivir más allá de unos pocos años o números. El cierre no tenía que ver con la censura directa del estado. En la mayoría de los casos éste se explicaba por falta de fondos. Otras, como Imago Mundi, perecieron cuando la normalización de la vida académica en 1955 hizo que sus mentores retornaran a la universidad. Paralelo a este resurgir de las revistas culturales, se dio en el país un auge de la industria editorial, que se había originado con la crisis de la industria española provocada por la guerra civil en dicha nación. Esto es tan notorio que los años 1936-1956 constituyen "el periodo de mayor prosperidad relativa de la industria editorial argentina y con toda certidumbre su periodo de mayor relevancia como productor internacional de libros" (Rivera 1980: 577). Aunque a partir de 1950 se pueden ver los primeros síntomas del deterioro posterior de la actividad, es evidente que durante los gobiernos de Perón el libro argentino no sólo produce divisas sino que se convierte en una mercancía de exportación. La ampliación de la industria editorial constituyó una oportunidad laboral para aquellos prohibidos por el gobierno, no sólo dirigiendo varias de las editoriales en expansión sino trabajando en las actividades paralelas que el boom editorial creó (traducción, corrección, edición, etc.) Sin embargo, nada de esto hizo más "digerible" el régimen, que para la mayoría de los intelectuales se traducía en la decadencia cultural del país.

¿Pero significó esto que los intelectuales ante la llegada de Perón se encerraron en sus propias instituciones, ya sea asociaciones, universidades paralelas, revistas o tertulias, e ignoraron los acontecimientos de la vida política? En otras palabras: ¿hubo algún espacio para ejercer la crítica al peronismo? Este lugar sí existió pero no hay que buscarlo en "clave política". La crítica intelectual se manifestó como una defensa del espíritu frente a un régimen que se les presentaba a la intelectualidad argentina como una afrenta de los valores de la civilización y la cultura. La oposición política estaba censurada, por lo que la crítica cultural permitía una serie de sutilezas y licencias que fueron utilizadas por los intelectuales. La guerra político-ideológica devino entonces en una guerra en defensa del espíritu, no exenta claro, de connotaciones de naturaleza política.

El primer gran enfrentamiento de la SADE con el gobierno de Perón revela la lógica de la "guerra" que los intelectuales entablaron contra el peronismo. Ésta se dio cuando la Comisión Nacional de Cultura presidida por el historiador nacionalista Ernesto Palacio -en ese entonces diputado por el peronismoquitó al historiador Ricardo Rojas del premio que había ganado en 1945 por su libro El profeta de La Pampa. Vida de Sarmiento y se lo otorgó a Pilar de Lusarreta, historiadora revisionista con una trayectoria mucho menor a la de Rojas, pero afiliada al partido gobernante. Rojas había sido candidato a senador nacional por el partido radical en las elecciones de febrero de 1946. Difícil 
es saber si despojarlo del premio fue una medida que le cobraba a Rojas dicha candidatura o como afirmó cínicamente uno de sus colegas "Sarmiento [tema del libro de Rojas] no era en ese entonces una figura de buen tono para ser presentada en una sociedad de gente piadosa, decente y ordenada". ${ }^{27}$ A pesar de que Rojas no era miembro de la SADE, ésta tomó la ofensa contra el escritor como una burla al gremio en su conjunto. La respuesta de la asociación fue entonces categórica, entregarle el premio mayor de la institución, el "Gran Premio de Honor", a Ricardo Rojas. SADE no fue de ese modo a la confrontación directa con el gobierno, no realizó un manifiesto público de rechazo y aunque el repudio a la medida era claro y dio lugar a fuertes declaraciones contra el gobierno, éstas quedaron confinadas a las reuniones de la institución. ${ }^{28}$ Tampoco intercedió a favor o en defensa de Rojas para que el gobierno lo resarciera del agravio cometido, sino que la institución le dio ella misma una especie de indemnización moral. De esa forma lo que la Sociedad de Escritores intentó hacer también fue legitimar sus propias credenciales culturales. Si los premios oficiales eran repartidos entre aquellos que expresaban su favor al gobierno los galardones de la SADE premiaban, por el contrario, el valor literario y los principios de quienes eran sus acreedores. ${ }^{29}$ De alguna forma la SADE salía fortalecida del "episodio Rojas". Con la entrega de su máximo galardón a Rojas venía a recomponer el orden jerárquico dentro del campo cultural del país que era destruido por el gobierno. Con esto los escritores evitaban la confrontación directa pero establecían una lucha velada en un espacio donde tenían más poder.

Desde el episodio sucedido con Ricardo Rojas el Gran Premio de Honor se constituyó en una especie de símbolo de la resistencia para los escritores de la SADE. De ahí en más y durante los años en que el peronismo fue gobierno, el premio fue entregado a escritores con claras credenciales "democráticas", muchos de ellos hostigados por el peronismo. Durante esa década la asociación otorgó el mencionado galardón a los escritores Eduardo Mallea, Ezequiel Martínez Estrada, Arturo Capdevilla, Baldomero Fernández Moreno, Francisco Romero, Alberto Gerchunoff, Enrique Banchs y Manuel Mújica Laínez. El

27 Giusti (1946).

28 Borges afirma en la entrega del premio que "la expoliación de que Rojas ha sido víctima es un eje más de esta melancólica serie que algunos llaman injusticia y otros nazismo". Si bien es cierto que las declaraciones de Borges son reproducidas en el Boletín de la institución al contrario de lo que hubiera sucedido unos años atrás, éstas no son material de un manifiesto dirigido al gran público. Borges (1946).

29 En el mismo discurso Borges afirma "al hacer suyo ese dictamen la Comisión directiva, le expresa, por mi intermedio, su adhesión y aplauso a los ideales democráticos que enaltecen su vida y su magnífica obra". Borges (1946). 
Premio de Honor, presentado por la propia SADE “como el más alto prestigio que puede aspirar un escritor en el país", ${ }^{30}$ era considerado no sólo un reconocimiento a la obra sino también a la trayectoria democrática del escritor acreedor del galardón. Era la puesta en práctica de aquello que Erro tan claramente expuso al recordar a Ricardo Rojas: "al escritor no sólo hay derecho a pedirle obras hermosas, sino también limpia conducta cívica". ${ }^{31}$ Para estos escritores la decisión sobre quién recaía el gran premio constituyó una forma de "resistencia silenciosa", una oposición imperceptible para el gobierno, pero que era una forma de ejercer y afirmar su poder dentro del campo intelectual. La "guerra" contra Perón era la "guerra" de la cultura contra la barbarie, y la forma de luchar significaba seguir controlando los circuitos culturales y desde allí ejercer la oposición del espíritu.

En el caso de la revista Sur, la defensa del espíritu constituyó notoriamente el eje sobre el cual se articuló el rechazo a Perón. Como ya se dijo, es imposible encontrar en las páginas de dicha publicación referencias directas al peronismo, pronunciamientos o manifiestos en contra de uno $\mathrm{u}$ otro acontecimiento político, sin embargo el discurso opositor nunca estuvo ausente. El grupo expresó su antiperonismo reiteradamente a través de la crítica cultural. La publicación analizó las distintas expresiones artísticas y culturales que nacieron bajo el amparo del estado peronista para oponerse a un régimen que, en sus propias palabras, los había sumido en la "indigencia espiritual". ${ }^{32}$ El centro de las diatribas era el nacionalismo cultural que se promovía desde el gobierno, y que enarbolaban los seguidores de Perón. Así por ejemplo, la escritora Estela Canto, describió en la revista los filmes de esos años como "falsos, lánguidos, casi intolerantes", características que asoció irónicamente a su "dosis de patrioterismo". ${ }^{33}$ El crítico literario español exiliado en Argentina Francisco Ayala, advirtió desde Sur sobre el prejuicio "de las literaturas nacionales", que en su parecer no tenían "otra realidad sino la de la afirmación ideológica, aspiración dictada por consideraciones o sentimientos de índole política, y en todos ajenos a la literatura misma". ${ }^{34} \mathrm{El}$ panorama de la pintura fue evaluado por el crítico de arte Felix Della Paolera, quien resumió con cierto humor la posición del grupo en torno al tema afirmando que "no se llegará a una plástica nacional por la mera acumulación de carretas, chiripás, coyás, ranchos, mates, aljibes, guitarreros, domas pericones o carreras de sortijas". ${ }^{35} \mathrm{El}$ revisionismo histórico

\footnotetext{
30 Erro (1957-1959).

31 Erro (1957-1959).

32 Olivera (1952: 147).

33 Canto (1950: 70).

34 Ayala (1951).

35 Della Paolera (1950: 68).
} 
-caricaturizado en una de las notas como "desinencia en ista"- fue también observado desde el mismo ángulo cuando fue descrito por Ayala como la "última fase, de la morbosa decadencia del espíritu público", que se estaba dando en el país. La crítica al revisionismo venía acompañada de una defensa de los héroes del liberalismo, como el caso de Esteban Echeverría, convirtiendo al centenario de su muerte en una fecha simbólica para la "resistencia antiperonista" (Aricó: 1988). Frente a la decadencia el grupo anteponía sus propios ideales, en donde la defensa del universalismo cultural era central. El antiperonismo de Sur se redujo entonces a una defensa de los grandes valores "del espíritu", de los que claramente el grupo se sentía poseedor legítimo. ${ }^{36}$

Las revistas que se crearon en esos días también nacieron con el mismo designio: ejercer la defensa de la cultura. Expresión, la publicación dirigida por los comunistas Hector P. Agosti, Enrique Amorín y Emilio Troise y por el socialista Roberto Giusti, aunque intentó una crítica más directa al gobierno, no pudo escapar de juicios parecidos a los de Sur. Uno de los artículos criticaba la sesión musical del Teatro Colón afirmando que el programa había sido escogido por Evita. ${ }^{37}$ De la misma forma, se abogaba por "trascender en literatura la simple nominación de lo nacional y recrear una figura del país física y espiritualmente verdadero". ${ }^{38}$ La revista Realidad, dirigida por el filósofo Francisco Romero, y en donde colaboraban varios intelectuales cercanos al liberalismo, entre ellos el ensayista Carlos Alberto Erro, el experto en educación Lorenzo Luzuriaga, y los escritores Ezequiel Martínez Estrada y Eduardo Mallea, puso el acento en analizar la crisis de occidente. Pero aunque en ella la defensa del espíritu, aparecía en un tono más universal, la connotación local no estaba del todo ausente. El manifiesto fundacional expresaba que los deberes de la cultura occidental: "-tal como han sido esbozados antes en el sentido de la lucha por la vigencia de valores universales capaces de configurar un esquema vital aceptable para todo el mundo y dotado de viabilidad históricagravitan sobre nosotros de manera particular, porque a nuestro alrededor prosperan tendencias negativas, fuerzas que empujan al mundo, no hacia aquel deseable programa de vida, sino hacia la disolución de todo principio espiritual y aun de toda cultura". Liberalis, tal cual como su nombre lo expresaba se creaba para defender los valores del credo liberal. En sus páginas se reunían más de ochenta intelectuales tan diversos como el escritor Ernesto Sábato, el abogado creador de Acción Argentina Rodolfo Fitte, el filósofo Vicente Fatone, el historiador Juan Canter y los incansables Erro y Giusti entre otros. La

36 Para una discusión y caracterización del grupo King (1989).

37 Hurtado (1947).

38 Fernández (1949). 
defensa del liberalismo era presentado en sus páginas como una reivindicación del individuo, "como la única razón valedera del pensamiento y de la libre iniciativa". ${ }^{39}$ El liberalismo se convertía en las páginas de la publicación en una plataforma desde donde juzgar la decadencia traída por el peronismo. Así la revista centraba sus diatribas contra el clericalismo, el hispanismo y el revisionismo histórico que describía como la suma de todas esas tendencias, como una "reacción oscurantista de origen y afán regresivo". ${ }^{40}$ El caso de esta revista revelaba más que ningún otro el lugar que el liberalismo, readquirió en esos años como mito unificador de la intelectualidad "democrática" en contra del peronismo.

La crítica cultural no era siempre clara o directa en su alusión a Perón. Poco a poco se fue creando un lenguaje en código que autores y lectores fueron aprendiendo y refinando. A veces la lectura requería cierta suspicacia para descifrar los ataques al gobierno. Las revistas utilizaban un lenguaje pleno de metáforas y alusiones no siempre evidentes. Por ejemplo, la publicación de Calígula por parte de Sur en 1946 era una forma de representar a Perón. Se hablaba de Europa y de Occidente como una forma de describir desarrollos y problemas locales. Así, aunque el análisis del escritor peruano Albert Wagner de Reyna publicado por Realidad sobre la posguerra no mencionara la situación local, era evidente la intención de los editores de la revista cuando publicaban un artículo que resumía la crisis actual afirmando que se podía describir con los "títulos de tres libros contemporáneos famosos: la rebelión de las masas, la decadencia de occidente, una Nueva Edad Media". ${ }^{11}$ Como observó el editor de Liberalis durante el periodo peronista, en la referencia a acontecimientos lejanos "trataban de reflejar ... el caso argentino" ${ }^{42}$ La crítica política más específica tampoco estuvo del todo ausente, pero ésta era presentada de una forma que se podía relacionar con los grandes valores de la civilización. El problema era presentado por estos intelectuales con rótulos como "la democracia de masas", avasalladora contra el individuo y las minorías, como el estatismo aniquilador de los derechos civiles; pero nunca con nombre y apellido.

Imago Mundi, la publicación dirigida por el historiador José Luis Romero, vio la luz cuando el régimen de Perón había avanzado en sus impulsos represivos, por lo que en ésta la alusión al peronismo fue casi inexistente. La publicación, pensada como vehículo de una determinada aproximación a la historia (la historia cultural), poco difería de las otras nacidas durante esos años: revis-

\footnotetext{
39 Liberalis (1949).

$40 \quad$ Liberalis (1953).

41 Wagner de Reyna (1947).

42 Liberalis, Junio de 1956.
} 
tas culturales que se ocupaban de distintos temas que hacían a la discusión intelectual. ${ }^{43}$ Dado el contexto en que se publica, no hay menciones en sus páginas sobre temas que se podrían relacionar con el peronismo, del mismo modo no hay artículos que se ocupen de problemas o cuestiones locales. Es decir en esta publicación, la crítica cultural no fue un vehículo para ejercer la crítica al peronismo. Sin embargo, es claro que lo que se busca desde esta revista como desde las otras, es garantizar que la vida intelectual sobreviva a los embates del gobierno y nuevamente se piensa en la guerra de los intelectuales contra Perón como "la guerra de la cultura contra la barbarie". Contorno representa un caso atípico dentro del universo intelectual antiperonista. ${ }^{44}$ La publicación, fundada en 1953 y que publicó bajo Perón seis números, reunía a un grupo de jóvenes que hicieron su debut durante el régimen de Perón. Entre éstos se encontraban quienes serían varios de los críticos literarios más conocidos de la siguiente década: los hermanos Viñas (Ismael y David), León Rozitchner, Noé Jitrik y Ramón Alcalde entre otros. La revista ponía el acento en la crítica literaria, tanto que ha sido considerada como el "momento inaugural de la irrupción de la crítica" en el país (Cella (ed.): 1999). La gran peculiaridad de ésta dentro del universo de la producción cultural de la época, es que la publicación representaba un grupo que buscaba distanciarse tanto del peronismo como del antiperonismo. Desde la óptica de estos jóvenes que buscaban "exorcizar genealogías", 45 el establishement intelectual antiperonista, representado por antonomasia en las figuras de Jorge Luis Borges y Victoria Ocampo, era tan nefasto como el peronismo. Si la crisis era tal como para permitir la llegada de un Perón, era también porque la intelectualidad había fracasado en entender el país, particularmente sus desafíos. El grupo cuestionaba las premisas que regían en el campo intelectual local, sobretodo el consenso liberal que se mencionó anteriormente y la falta de compromiso de los letrados, que se expresaba en la práctica de una literatura de "evasión" ${ }^{46}$ El antiperonismo era visto desde las páginas de la publicación como una posición simplista, que dividía la realidad entre el imperio del bien y del mal; entre el "reino de los Santos y los abyectos" según un artículo de David Viñas. A la vez que

43 Para una discusión sobre el tema ver Luna (1976: 138). Para un estudio sobre Imago Mundi, Acha, (1999).

44 La misma ha ejercido una notoria fascinación dentro de la crítica literaria justificada más por consideraciones posteriores -como la de proveer un "linaje" a la intelectualidad progresista local o por la importancia que varios de sus colaboradores alcanzaron en los años venideros- que por la influencia real que ejerció en aquel contexto. Plotkin y González Leandri (2000).

45 Gorini Juan José, (seudónimo de David Viñas) (1952).

46 Alcalde (1955). 
no lograba advertir que el peronismo era parte de la realidad "y que no cabía condenarla imponiéndole el sayo amarillo." Pero tales declaraciones eran seguidas por otras, que censuraban de igual forma al peronismo al que resumían como una opción "entre el sí definitivo o la aniquilación, el acatamiento integro o la eliminación". ${ }^{47}$ Por lo que a pesar de las obvias diferencias con otras publicaciones, hasta antes del golpe de 1955, para los colaboradores de Contorno al igual que para los criticados "letrados consagrados" el peronismo imposibilitaba cualquier desarrollo cultural o intelectual y era tan reprochable como su contra cara.

\section{La Represión contra "la vida del espíritu"}

El desdén de Perón por la cultura de elite fue notorio. Su gobierno no tuvo una política cultural clara. La gran innovación de su gestión fue la gratuidad y la masificación de la cultura, pero más allá de eso, no hubo un intento gubernamental por cambiar los modelos culturales hegemónicos. Tampoco existió un plan sistemático para atraer intelectuales, que podría haber facilitado dicha labor cultural. ${ }^{48}$ Las tentativas en este sentido no fueron más allá de un proyecto aislado -que tenía que ver con la necesidad de reducir la oposicióncomo fue el de crear una gran confederación de letrados (la Junta Nacional de Intelectuales). A pesar de que Perón subrayó en varias ocasiones la centralidad de la cultura en 1949, lo escuchamos decir que todavía la obra en dicho terreno no ha sido comenzada, ya que la obra social viene primero. ${ }^{49}$ Un año después, en 1950, hablando ante los pocos letrados que lo apoyan el presidente reconoce que aún "no [ha] podido todavía invadir, algunos horizontes, especialmente el de los intelectuales". ${ }^{50}$ La consecuencia "feliz" de esta situación fue que no hubo una política sistemática de dominación de los ámbitos letrados, como si existió por ejemplo en torno a los medios masivos de comunicación sobre los cuales el gobierno utilizó diversas medidas en pos de ejercer un control total. Sin embargo, esto no quiere decir que el campo intelectual antiperonista no sufriera los embates de un régimen que hacía recurrente uso de mecanismos autoritarios en otros ámbitos. El hecho de que en los primeros años de la administración de Perón la crítica cultural ocupara el lugar de la

\footnotetext{
47 Viñas (1954).

48 El peronismo también marginó a sus propios intelectuales. Figuras del ámbito letrado como Arturo Jauretche o Raúl Scalabrini Ortiz, para 1950 ya habían sido silenciadas dentro del peronismo.

49 Perón (1949).

50 Perón (1950).
} 
oposición se debía a que existía entre la intelectualidad y el estado una suerte de acuerdo tácito: mientras las actividades de los letrados no rebasaran los límites de las elites, el gobierno hacía oídos sordos. Y si en los primeros años esto funcionó, aunque con momentos de tensión -las asociaciones culturales como la SADE siguieron actuando normalmente, lo mismo que las publicaciones- desde principios de 1950 se comienza a notar el efecto creciente de la censura en el campo intelectual.

No es posible poner una fecha clara al aumento de la represión de la "vida del espíritu", pero los primeros indicios ya son visibles a partir de 1950, para hacerse más numerosos a medida que nos acercamos a la segunda presidencia de Perón, hechos que se correlacionaban con un contexto de mayor polarización política. ${ }^{51}$ En 1950 una ley reglamentada recién en 1952 sancionó la reorganización de las academias profesionales. Entre otras cosas, dicha ley estipulaba que la designación de los académicos de número debía ser aprobada por el Poder Ejecutivo y que los miembros de más de sesenta años de las academias existentes debían retirarse. ${ }^{52}$ Más que el cambio significativo en la orientación y dirección de dichas instituciones, las intervenciones se tradujeron en una especie de clausura de hecho, dado que las academias interrumpieron sus actividades a partir de 1952. La principal sede del CLES en la ciudad de Buenos Aires fue cerrada, lo que resultó en que sus filiales del interior (Bahía Blanca y Rosario) se convirtieran en sus centros de actividades. En SADE, el giro autoritario del gobierno contra el mundo intelectual fue evidente cuando en agosto de 1952 la institución fue impedida de realizar su Sesión Extraordinaria, en la cual se debían elegir nuevas autoridades. En ese entonces el presidente de la sociedad de escritores era Jorge Luis Borges. De acuerdo a lo estipulado por el estatuto, en caso de que no pudieran elegirse nuevas autoridades, las viejas debían permanecer en el cargo. Borges se vio obligado entonces, por la censura del gobierno, a ser presidente un año más de lo que le correspondía. Si bien la institución ya había tenido algunos conflictos aislados con el poder político, en ninguno de ellos la misma existencia de la sociedad había estado en riesgo. Frente al que era sin lugar a dudas el mayor asedio, la SADE buscó por todos los medios posibles que entrarían dentro de la categoría de "diplomáticos" el fin de la restricción. La asociación no fue a la confrontación y se abstuvo de condenar al gobierno públicamente. Aunque informó inicialmente a la prensa y a sus asociados de lo que estaba sucediendo, los intentos de terminar con la

51 Basta sólo recordar que en septiembre 1951, Perón tuvo que enfrentar el primer intento serio de golpe de estado, liderado por el general Benjamín Menéndez.

52 Para el caso de la Academia de Historia ver Quattrocchi-Woisson (1995: 281) y para una discusión más general sobre el efecto del decreto reglamentario ver Flavia Fiorucci (2005). 
prohibición gubernamental oscilaron entre cartas al delegado de la policía federal, al inspector de Justicia (que debía labrar las actas) y al ministro del Interior. ${ }^{53}$ Finalmente un año después, en agosto de 1953, una comitiva de la SADE que se reunió con el ministro Borlenghi consiguió que éste autorizara la realización de la Asamblea necesaria para reelegir las autoridades. ${ }^{54}$

Los hechos indicaban que el gobierno ya no estaba tan dispuesto a aceptar el dominio de los sectores antiperonistas sobre la cultura. En abril de 1953, durante una concentración en la plaza de Mayo, en la que hablaba Perón, estallaron bombas colocadas por grupos opositores. El saldo de las explosiones fue varias personas muertas y una escalada de violencia poco antes vista. Los incendios al Jockey Club, a la Biblioteca de la Casa del Pueblo, a la Casa Radical y al Comité Conservador, fueron la respuesta a las bombas. El gobierno reaccionó encarcelando indiscriminadamente opositores, entre abril y mayo se detuvieron a 4000 personas (Luna 1987: Tomo III, 48). Varios escritores de la SADE quedaron entre rejas. Entre ellos la de casi toda la Comisión entera de ASCUA, una asociación que desde hacía sólo unos meses reunía a intelectuales antiperonistas con el lema de defender la tradición de mayo. ${ }^{55} \mathrm{El}$ poco antes presidente de la sociedad de escritores (1948-1950) Carlos Alberto Erro -uno de los fundadores de ASCUA- quedó entre los encarcelados con sus compañeros en dicha empresa, entre los que se encontraban varios escritores miembros de SADE como Julio Aramburu, José Barreiro, Víctor Massuh, Carlos Manuel Muñiz, Norberto Rodríguez Bustamante y Francisco Romero. ${ }^{56} \mathrm{La}$

53 Ver Actas $\mathrm{N}^{\circ} 509$ hasta $\mathrm{N}^{\circ} 521$, de agosto de 1952 a agosto de 1953.

54 Roberto Giusti cuenta en sus memorias esta visita al ministro del Interior ingeniero Borlenghi. De acuerdo a lo declarado por Giusti, Borlenghi no comprendía por qué los escritores no estaban alineados con Perón. Giusti (1994: 262).

55 La asociación, fundada por un grupo reunido alrededor del ensayista Carlos Alberto Erro en 1952, se postulaba como un espacio para discutir los problemas del país. La creación de ésta se originaba en gran parte en la frustración que causaba a varios intelectuales el "abandono de la lucha" que se hacía desde tribunas como la SADE. Las declaraciones de Erro en el primer boletín, en las que acusaba a la inteligencia de ser "frustrada y estéril", a la vez que abogaba a que ésta se constituyera en "algo más que una espectadora ingeniosa o divertida de la realidad argentina", ilustraban claramente el porqué de la asociación. Sin embargo, desde un principio ASCUA no logró los fines con que había sido creada, convirtiéndose en otra tribuna más del repertorio de temas que se repetían una y otra vez en los distintos ámbitos: el revisionismo histórico, la generación del 37, la libertad entendida en sentido abstracto. La asociación no fue la plataforma para una militancia más activa. Como lo observó años más tarde en una devastadora crítica el escritor comunista Héctor Agosti, ASCUA fracasó en "elevarse sobre el vacuo liberalismo". Erro (1953) y Agosti (1959: 141).

56 La Comisión directiva de ASCUA estaba formada por: Carlos Alberto Erro, Julio Aramburu, Daniel A. Seijas, Isaac Maguid, José Fornaroli, José P Barreiro, Cupertino del 
lista de detenidos miembros de SADE era sin embargo más vasta, escritores que no pertenecían a ASCUA también quedaron en la redada. Entre otros, el poeta Enrique Banchs, la directora de la revista Sur Victoria Ocampo y el catedrático Vicente Fatone, fueron a parar a la cárcel. Si bien nunca se supo quiénes fueron los responsables de las bombas, difícilmente estos intelectuales tuvieron algo que ver con dichos actos de terrorismo.

Dependiendo de los casos los escritores permanecieron alrededor de cuarenta días encarcelados. La pregunta que los hechos descritos suscitan es: ¿Qué hizo la SADE, como entidad gremial de los escritores, para defenderlos y para garantizar la libertad intelectual? ¿Qué hizo la SADE para defender a quién fuera su presidente anterior? A pesar que la institución había reducido sus niveles de politización, ésta tenía un declarado compromiso con las libertades que hacían a la tarea intelectual. ${ }^{57}$ Pero cuando ese compromiso era tal vez más necesario que nunca, considerando que el momento político no estaba para la confrontación, la SADE decidió abstenerse de salir en defensa de sus asociados. ${ }^{58}$ Ésta fue claramente una decisión unilateral de la Comisión Directiva presidida por Borges dado que en ese entonces la sociedad estaba impedida de realizar asambleas. ¿Temió la SADE que una confrontación así con el gobierno le costaría el cierre total de la institución? Si éstas eran las razones es necesario afirmar que las mismas no fueron un obstáculo para el gremio de los periodistas. El Círculo de Prensa se entrevistó con el ministro Borlenghi para obtener la libertad de los periodistas y escritores detenidos. ${ }^{59}$ La actitud de la SADE fue duramente criticada por varios de sus miembros. Leónidas Barletta, ex presidente de la asociación, fue uno de los opositores más claro a la actitud asumida por la sociedad de escritores. En una de sus alusiones a estos hechos Barletta se preguntaba por las razones que motivaron que los escritores no defendieran a sus colegas: "Si es por miedo, ¿miedo de qué?”; afirmaba Barletta, “¿de qué los encierren? ¿Y acaso no es mejor estar entre rejas con el respeto y la gratitud emocionada de los jóvenes que nos suceden, que estar en el cómodo gabinete escribiendo con suma cautela sobre Sarmiento y Echeverría,

Campo, Rodolfo Fitte, José Santos Gollan, Víctor Massuh, Carlos Manuel Muñiz, Jaime Perriaux, Héctor Raurich, Norberto Rodríguez Bustamante, Francisco Romero, Ernesto Sábato y Ángel M. Zuloaga.

57 En esos momentos en que se dieron conflictos entre el estado y la SADE, ésta había respondido alegando ese compromiso.

58 La razón por la que la SADE no defendió a sus propios escritores quedó clarificada recién un año después cuando la SADE se negó a defender a Carlos Agosti, que también había sido encarcelado. En ambos se consideró que el ambiente político no era propicio para dicha defensa. Acta $\mathrm{N}^{\circ}$ 543, SADE, 27 de julio de 1954. 
soportando la sonrisa desdeñosa de quienes se sienten defraudados por una conducta que no puede ser nunca la de un intelectual?". ${ }^{60}$

¿Pero existió la actitud que reclamaba Barletta entre los intelectuales? Lo cierto es que los reclamos del escritor de Boedo parecen haber tenido poco eco. Los intelectuales continuaron "en sus gabinetes". En la constelación de revistas antes citadas tampoco aparecen mencionados los arrestos, ni las prohibiciones por las que pasaba SADE y el CLES. La crítica cultural cruzada seguía siendo usada como discurso de oposición, pero ante los hechos, su significación ya no era la misma. La revista Sur cuya directora quedó entre las prisioneras publicó las cartas de Antonio Gramsci desde la cárcel recurriendo a una obvia metáfora. En la figura del pensador italiano -asediado por el fascismo- los intelectuales se representaban. En 1949, desde Liberalis, Francisco Ayala ya había resumido la actitud que tomaron los intelectuales antiperonistas:

El escritor, a la fecha, mas bien tendrá que reducirse a una especie de clandestinidad, de estrecha, oscura, disimulada, secretísima confabulación, dejándose despojar de todo, abandonando cualquier pretensión de influjo directo sobre el mundo, a cambio de preservar tan solo sus palabras mas desnudas. ${ }^{61}$

Leída la cita desde la perspectiva personal de Ayala, la misma tenía un significado nítido. El autor, un exiliado español en Argentina, proponía el exilio inter-

60 Leónidas Barletta, Carta a Manuel Gálvez, Buenos Aires, 12 de diciembre de 1953, Archivo Personal de Gálvez, Academia Argentina de Letras. El ex presidente de la institución Leónidas Barletta -quien por propia iniciativa se reunió con varios otros escritores para pedir por los presos políticos- expresó en reiteradas ocasiones su rechazo a la actuación de la SADE y todos aquellos que se negaron a interceder por sus colegas encarcelados. La cita transcrita arriba es parte de una carta, dirigida al escritor Manuel Gálvez a quien Barletta había invitado a participar en la defensa de los presos pero que se había negado alegando la filiación comunista del ex presidente de la SADE. Barletta criticó tanto la actitud de Gálvez como la de sus colegas de SADE. Desde su publicación -Propósitos - volvió en reiteradas ocasiones sobre estos hechos. Lo cierto es que del otro lado, la actitud de Barletta también resultó inaceptable para muchos de sus colegas. De modo de interceder por los presos este último se asoció con escritores que eran confesos peronistas y firmó con ellos un petitorio. Entre los firmantes estaba el enemigo más claro de la SADE: su anterior socio, Leopoldo Marechal. Para los escritores antiperonistas de SADE ésta era una actitud inaceptable. Los límites eran claros, no podía haber convivencia alguna con los peronistas, ni aún para interceder por los colegas encarcelados. Giusti a la distancia dirá que no firmó el petitorio porque consideró que "los amigos presos eran quienes más se oponían a obtener la libertad por ese camino oblicuo". Giusti (1994: 262). Ver además "Un grupo de escritores solicitó la libertad de varios colegas detenidos" en La Prensa, 13 de junio de 1953:5 y Barletta (11 de agosto de 1955).

Ayala (1949). 
no como una solución, como una actitud moral. Durante el año y medio que siguió al encarcelamiento masivo de intelectuales, la represión en el sector continuó. El curso de acción de los letrados y de sus asociaciones -es decir "encerrarse en sus gabinetes" - tampoco cambió hasta que fue evidente que el régimen se agotaba. La SADE prosiguió negándose a defender a los escritores encarcelados. Por ejemplo, en julio de 1954, la asociación se rehusó a interceder en el Ministerio del Interior por el encarcelamiento del escritor comunista Carlos Agosti, quien era un miembro activo de la institución. Las revistas tampoco iniciaron una discusión sobre el tema o mencionaron los hechos durante dicho periodo.

Para mediados de 1955, la Argentina era una sociedad en crisis. El conflicto que el gobierno sostenía con la iglesia había derivado en la polarización de la sociedad entera. Había indicios certeros de que el gobierno peronista estaba agonizando. Los rumores de golpes y conspiraciones abundaban, se sentía como lo llamó Federico Neiburg (1998: 181) “una sensación de vísperas”. Era claro que algo estaba por cambiar y así lo percibió la SADE que dejó de juzgar inoportunas las negociaciones por sus afiliados aún cuando la policía seguía prohibiendo las reuniones de la sociedad y comenzó a interceder por sus asociados encarcelados. ${ }^{62}$ Por primera vez desde octubre de 1945, la asociación expuso sin tapujos su opinión con respecto a la situación política del país. Ante el pedido de pacificación del presidente que siguió al intento golpe estado en junio de ese año, la sociedad de escritores envió a principios de agosto un comunicado a la prensa en el que abogaba por el fin del estado de guerra interna declarado por el ejecutivo el cual permitía al estado violar las libertades individuales. A la vez que dejaba claro en dicho manifiesto que la pacificación sólo iba a tener viabilidad si antes el gobierno terminaba con la represión a la oposición y por supuesto a la institución en particular. El manifiesto declaraba que sólo "suprimiendo las detenciones sin causa, sin juicio y sin explicación, y dejando sin efecto las prohibiciones de actos literarios" se iba a dar un gran paso en pos de la paz interna. ${ }^{63}$

La respuesta de la SADE ante el pedido de pacificación poco se diferenciaba de la que habían pronunciado otras fuerzas de la sociedad civil. Lo que debe sorprender es en cambio el hecho de que la institución se manifestó públicamente en un estilo que mucho tenía que ver con la SADE de principios de los 40. Había un evidente paralelismo entre el manifiesto de agosto del 55 y el manifiesto fechado 10 años antes en agosto del 45 en donde la sociedad aboga-

62 Desde principios de 1955 la SADE volvió a interceder ante el ministro del Interior por los asociados presos alegando "el deber que la sociedad (tenía para) un colega en ese trance". Ver Acta $\mathrm{N}^{\circ}$ 556, SADE, 21 de marzo de 1955; Acta $\mathrm{N}^{\circ}$ 557, SADE, 4 de abril de 1955, Acta $\mathrm{N}^{\circ}$ 558, 18 de abril de 1955,

63 Acta $\mathrm{N}^{\circ}$ 564, SADE, 8 de agosto de 1955. 
ba por el retorno a la normalidad constitucional. ${ }^{64}$ Aunque aún era demasiado temprano -Perón seguía siendo presidente- la SADE se estaba preparando para los días que venían, quien tuviera un pasado antiperonista iba a ser beneficiado.

\section{Un pasado glorioso}

En la mañana del 20 de septiembre de 1955, Perón entró en la embajada de Paraguay para comenzar un periodo de casi dos décadas de exilio. Un golpe de estado, conocido como la Revolución Libertadora, liderado por fuerzas militares y apoyado por civiles terminó con el segundo gobierno peronista. Numerosos son los testimonios que prueban el alborozo con el que la "intelectualidad democrática" recibió la caída de lo que consideraba un régimen de diez años de oprobio. Comenzaba el tiempo de la "reconstrucción nacional" como rezaba la consigna que daba título al número de Sur posterior al peronismo; o como se declaraba desde Liberalis, el "campo (estaba) despejado"65 para la tarea intelectual. Pronto fue evidente que detrás de la alegría de los letrados había un proyecto claro: los intelectuales buscaban posicionarse en un lugar clave para colaborar en la mencionada "reconstrucción". Éstos buscaban reconquistar los espacios perdidos, como por ejemplo en la universidad, y reafirmar su poder. Un análisis de los mismos testimonios que siguieron a la denominada Revolución Libertadora, muestra como esta intención fue siempre evidente. Por ejemplo en el hoy mítico $\mathrm{N}^{\circ} 237$ de Sur, es notorio como los intelectuales se adjudican un rol preponderante en la nueva Argentina. "El sector culto de nuestro pueblo", postula uno de los artículos, "debe proyectar su cultura sobre la zona inculta, vincularse con sus temores y sus necesidades, ser para ella la proa de la nave" ${ }^{66} \mathrm{Si}$ la "administración depuesta (había propiciado) la perversión intelectual y moral", ${ }^{67}$ como resumía Hugo Cowes también desde Sur, no había duda de porque los intelectuales estaban llamados a cumplir un rol protagónico. Eran los "educadores", los letrados, los que tenían "deberes ineludibles" ante "la crisis espiritual de la época". ${ }^{68}$ Pero quién se adjudica la tarea de "reconstruir el país", también busca el poder para hacerlo.

En SADE el proyecto de los letrados fue más explícito que en ningún otro lugar, tal vez por el hecho de que la institución se presentaba como una asociación que buscaba la representación orgánica de los intelectuales. Pero también

\footnotetext{
64 Acta $N^{\circ}$ 388, SADE, 31 de julio de 1945.

65 "Frente al campo", Liberalis (1956).

66 Peralta (1955: 113).

67 Cowes (1955: 122).

68 Mantovani (1955: 19).
} 
fue ahí donde éste reveló sus aristas “menos dignas". Luego de producido el golpe, en un comunicado público la institución expresó su adhesión a la nueva administración, pero al mismo tiempo sacó a relucir sus propias historia de resistencia antiperonista y consecuente persecución. ${ }^{69}$ El fin del peronismo determinó una batalla dentro del campo intelectual para apropiarse de una supuesta tradición antiperonista. ${ }^{70} \mathrm{La}$ SADE se construyó una historia de militancia opositora que claramente no coincidía con lo actuado por la institución si recordamos que se negó a defender a sus miembros. Ese pasado (en parte real y en parte "inventado") operaba como una legitimación más allá de cualquier cuestionamiento y transcendía los límites de SADE. La historia era construida a través de ciertos datos, quién había sido exonerado de la universidad, o se había visto perjudicado de alguna forma por el gobierno se convertía automáticamente en un antiperonista militante. Lo mismo era aplicable para SADE, si fue perseguida eso sucedió porque era ésta una voz de la oposición. Cuando estos datos no resultaban suficientes, el mismo silencio, la "no-colaboración" de sus escritores se presentaba como la evidencia del pasado antiperonista de la agrupación y de sus miembros. Como afirmó uno de sus poetas asociados, Enrique Fernández Latour: "con sólo negarse a las genuflexiones de rigor, con sólo mantenerse en la SADE, ese benemérito reducto de la inteligencia libre salvaron su dignidad y la de nuestras letras". ${ }^{71}$ Ese pasado "construido" era una historia que operaba como una fuente de legitimidad hacia el futuro. Roberto Giusti lo expresó con claridad al afirmar que:

Válidos de esta fuerza moral que nos concede un pasado limpio, los afiliados de la SADE tenemos el derecho, no digo a ejercer represalias, pero si a mantenernos vigilantes para exigir que no sean indultados moralmente los que pecaron contra la libertad de la inteligencia. ${ }^{72}$

69 El comunicado expresa que la institución "celebra con júbilo el fin de un régimen que cercenaba el ejercicio de los más sagrados derechos de la ciudadanía y de la cultura", a la vez que señala que "durante largo tiempo esta sociedad vio trabadas sus actividades. Sus conferencias, sus cursos de arte y de literatura y sus reuniones de difusión intelectual fueron prohibidas. Muchos de sus asociados, conocidos profesores y escritores, sufrieron persecución y encarcelamiento, y no pocas veces la entidad debió afrontar la difamación". Ver SADE, Acta $N^{\circ}$ 569, 24 de septiembre de 1955.

70 La batalla tomó ribetes casi ridículos cuando desde las páginas de la revista Mayoría se desarrolló una polémica sobre la participación de escritores de la institución en revistas peronistas. Para el bando "peronista" el sentido de la polémica era "demostrar que hubo vinculación cultural entre el peronismo oficialista y el antiperonismo oficial". Para los escritores de la SADE la intención era negar "cualquier tipo de colaboración". Ver Finnegan (5 de febrero de 1959) Pineda (26 de marzo y 16 de abril de 1959).

72 Giusti (1957-1959). 
El proyecto de los escritores había sido puesto al desnudo bien temprano cuando una delegación de la SADE visitó al presidente provisional, el general Lonardi, para "agradecer la distinción nominativa a miembros de la institución" en puestos de gobierno. ${ }^{73}$ Entre otros Jorge Luis Borges había sido nombrado director de la Biblioteca Nacional, José Luis Romero interventor de la Universidad de Buenos Aires, Vicente Barbieri director de la revista El Hogar, Ernesto Sábato director de la publicación El Mundo, Roberto Giusti director del Instituto de Literatura Iberoamericana de la UBA, Vicente Fatone embajador en la India. Adjudicándose con éxito ese pasado "gloriosamente antiperonista" los escritores conquistaron con creces los espacios de poder perdidos. El hecho de que el nuevo gobierno los escogiera para puestos claves, como dirigir la Biblioteca Nacional o intervenir la Universidad de Buenos Aires, implicaba aceptarlos como símbolos de la resistencia antiperonista. Del otro lado, también es cierto que la "alianza" entre los intelectuales y los militares "libertadores" constituyó una fuente de legitimidad para el gobierno y que garantizó que en muchos casos la adhesión de los intelectuales a la nueva administración fuera de carácter incondicional. ${ }^{74}$ Un mes después del golpe, Cortázar, observaba desde París que el hecho de que muchos de sus amigos fueran llamados a ocupar "puestos importantes prueba por parte del gobierno la buena voluntad de llevar gente honesta a las funciones públicas". ${ }^{75}$ Es así como en 1955, el pasado antiperonista (no siempre a la altura de lo que se podría denominar el compromiso de un intelectual) se convirtió en una carta de presentación, en una oportunidad para la intelectualidad. Pronto, iban a aparecer nuevos conflictos, que iban al menos a "desafiar" la victoria ganada con la libertadora y que iban a comprometer seriamente el consenso del antiperonismo intelectual, quebrando nuevamente el campo.

\section{Consideraciones finales}

No caben dudas de que el antiperonismo fue hegemónico dentro del campo intelectual. La oposición de los letrados a Perón era una consecuencia lógica de los conflictos que dividían a los intelectuales locales desde mediados de los años treinta, cuando la política se convirtió en una obvia frontera de demarca-

73 Ver SADE, Acta $\mathrm{N}^{\circ}$ 570, 4 de octubre de 1955 y Acta $\mathrm{N}^{\circ}$ 571, 18 de octubre de 1955.

74 Ante varias denuncias por la represión creciente del gobierno, varios intelectuales firman un manifiesto de apoyo incondicional. Ver "Los escritores declaran fe en la revolución”, La Nación, 24 de septiembre de 1956.

75 “Carta de Julio Cortázar a Jean Barnabé, 31 de octubre de 1955”, Bernández (ed.) (2000: 327). 
ción en el campo cultural. El análisis de los circuitos culturales opositores a Perón entre el periodo 1945-1956 permite concluir que la oposición a Perón constituyó una clara "generadora de consenso" y "cohesión" entre la intelectualidad autoproclamada democrática, en donde liberales y comunistas compartían un mismo frente de lucha. Lo mismo también significó un boom de la "vida de la cultura", en el sentido en que varias revistas se fundaron en estos años y antiguas instituciones como la SADE o el CLES adquirieron un valor aún más importante, porque se convertían en los "espacios" donde la cultura podía seguir "sobreviviendo". Desde éstos se ejercía la defensa de la vida del espíritu, que como se mencionó fue la forma en que los intelectuales expresaron su rechazo a Perón. El movimiento peronista fue interpretado por los letrados no sólo como un gobierno autoritario, sino sobretodo como la consumación de un proceso de decadencia y alienación cultural. Constituía la evidencia de la mediocridad del país. Ante esto la guerra de los letrados se convirtió en la guerra de la defensa del espíritu. La "crítica cultural" permitía a los escritores ciertas "sutilezas" que hacían que no peligrara la misma existencia de sus instituciones culturales. El discurso de oposición al peronismo consistía entonces en un lenguaje de códigos y señales al que lectores y escritores se acostumbraron. Esto implicaba que la resistencia era silenciosa y como lo subraya Jordi Gracia, al describir la actitud de los intelectuales liberales ante Franco, "cuando la resistencia es silenciosa es porque no ha sabido ser ruidosa, ni pletórica y alegre y vital y explosiva, sino acobardada, timorata, precavida, cauta y muy poco heroica". ${ }^{76}$

Pero aún a pesar de los esfuerzos de la inteligencia antiperonista de no provocar al gobierno, a medida que se acerca la segunda presidencia de Perón (1952), la represión la toca de cerca y varios intelectuales son encarcelados y sus instituciones censuradas. De forma casi predecible la "censura gubernamental" se traduce en un incremento de la "autocensura" por parte de los letrados. Si bien éste puede ser visto como un comportamiento racional significó el abandono de lo que para muchos es el compromiso de un intelectual. En el lugar donde esto fue más evidente fue en la SADE, institución creada para defender a sus asociados, que se negó a interceder por la libertad de sus socios encarcelados. El hecho de que los mismos escritores mandaran cartas a la institución pidiendo la mediación de la SADE, prueba que su defensa era una conducta que se esperaba del gremio de los letrados. Lo paradójico de la situación, es que a pesar de la falta de dicho "compromiso", cuando Perón cae en septiembre de 1955, el antiperonismo deviene en fuente de legitimidad para los intelectuales democráticos. El "pasado antiperonista" es la plataforma que los intelectuales usan para posicionarse en la Argentina que viene. Los intelec-

Gracia (2004:19). 
tuales consiguen éxitos claros en esta operación. El gobierno los elige para -ahora sí desde el estado- legislar sobra la vida intelectual y desde allí colaborar en la denominada "desperonización" del país. Todo esto revela por otro lado la incapacidad del gobierno de Perón de "quebrar" la hegemonía antiperonista sobre la cultura. Durante esos 10 años, la vida cultural continúo funcionando a la par del estado, y cuando fue necesario, los intelectuales ya estaban preparados para el recambio.

\section{Bibliografía y fuentes citadas}

Actas de la Sociedad Argentina de Escritores (SADE).

Acha, José Omar (1999): “Imago Mundi (1953-1956) en una coyuntura historiográficapolítica”. En: Prismas, 3, pp. 117-142.

Agosti, Hector (1959): El mito Liberal. Buenos Aires: Ediciones Procyon.

Alcalde, Ramón (1955): “Imperialismo, cultura y literatura nacional”. En: Contorno, 5/6, Septiembre. Reproducido en Carlos Magnone y Jorge Warley (eds) (1993): Contorno Selección. Buenos Aires: Centro Editor de América Latina, pp. 133-143.

Altamirano, Carlos (2000): Peronismo y cultura de izquierda. Buenos Aires: Temas Grupo Editorial.

- y Beatriz Sarlo (2001): Bajo el signo de las masas (1943-1973). Buenos Aires: Ariel.

Amadeo, Mario (1956): Ayer, Hoy y Mañana. Buenos Aires: Ediciones Gure.

Amorín, Enrique (1945): "Sobre la paz". En: Sur, 129, julio, p.p 71-72.

Aricó, José (1988): La cola del diablo. Buenos Aires: Punto Sur.

Arrieta, Roberto/Giusti, Roberto y otros (1980): La profesionalización de la crítica literaria. Buenos Aires: Centro Editor de América Latina.

Ayala, Francisco (1949): "El Escritor”. En: Liberalis, 2, Julio-Agosto, pp. 34-35.

— (1951): “El escritor”. En: Sur, 203, septiembre, pp. 6-19.

Barletta, Leónidas (1955): “Problemas del escritor”. En: Propósitos, 11 de agosto.

Bernández, Aurora (ed.) (2000): Julio Cortázar-Cartas 1937-1963. Buenos Aires: Alfaguara.

Boletín de la Asociación Cultural Argentina para Defensa y Superación de Mayo (Buenos Aires).

Boletín de la Sociedad Argentina de Escritores (SADE) (Buenos Aires).

Borges, Jorge Luis (1946): "En forma de parábola". En: Boletín de la SADE, XIV, p. 29.

— "Palabras pronunciadas por Jorge Luis Borges en la comida que le ofrecieron los escritores”. En: Sur, 142, pp. 114-115.

Bottos, Patricio (2000): “Antifascismo en la Argentina: los orígenes de la Unión Democrática, 1936-1946”. Trabajo de Licenciatura. Buenos Aires: Universidad de San Andrés.

Buchrucker, Cristián (1987): Nacionalismo y Peronismo. La Argentina ante la crisis ideológica mundial. Buenos Aires: Editorial Sudamericana. 
Cane, James (1997): "Unity for the Defense of Culture": the AIAPE and the Cultural Politics of Argentine Antifascism, 1935-1943”. En: Hispanic American Historical Review, 77, 3, pp. 443-469.

Canto, Estela (1950), “Almafuerte”. En: Sur, 185, pp. 70-72.

Cella Susana (ed.) (1999): Historia crítica de la literatura Argentina. Buenos Aires: Emecé.

Codovilla, Vittorio (1946): Batir al naziperonismo. Para abrir una era de libertady progreso. Buenos Aires: Ed. Anteo.

Contorno (Buenos Aires).

Cowes, Hugo (1955): "Nuestra enseñanza secundaria". En: Sur, 237, noviembrediciembre, pp. 121-124.

Della Paolera, Félix (1950): “Exposición de Juan Batlle Planas”. En: Sur, 183, pp. 68-70.

Dickmann, Enrique (1939): La infiltración nazi-fascista en Argentina. Buenos Aires.

Dolkart, Ronald H (1999): “The Right in the Década Infame, 1930-1943”. En: Mc Dee Deutsch, Sandra (1999): Las Derechas. The extreme right in Argentina, Brazil and Chile 1890-1939. Stanford: Stanford University Press.

Erro, Carlos Alberto (1957-1959): "Manuel Mújica Láinez-Gran Premio de Honor 1955-1956”. En: Boletín de la Sociedad Argentina de Escritores (SADE), pp. 17-18.

- (1953): "Porque nos basamos en Mayo", Boletín de la Asociación Cultural Argentina para Defensa y Superación de Mayo, 1, Septiembre.

Expresión (Buenos Aires).

Fernández Torres, M. A. (1949): “El aporte del interior a la literatura nacional”. En: Expresión, 3.

Finnegan, Patricio (1959): "Si los escritores auténticamente democráticos se negaron a tener ningún contacto con el peronismo, no cabe duda de que la SADE está poblada de intelectuales totalitarios". En: Mayoría, 5 de febrero de 1959, p.28.

Fiorucci, Flavia (2001): "Los escritores y la SADE: entre la supervivencia y el antiperonismo. Los límites de la oposición (1946-1956)”. En: Prismas, 5, pp. 101-125

- (2005): "Reflexiones sobre la gestión cultural bajo el Peronismo". En: Actas de las X Jornadas Interescuelas/Departamento de Historia, Universidad Nacional de Rosario, septiembre 2005.

Giusti, Roberto (1957-59): "Roberto Giusti-Gran Premio de Honor 1957-1958". En: Boletín de la Sociedad Argentina de Escritores. 1957-1959. Buenos Aires: SADE, pp. 55-61.

- (1946): "Perfil del tiempo -Actos de Fe". En: Expresión, I, p. 80-81.

- (1994): Visto y Vivido. Buenos Aires: Ediciones Teoría.

Gorini, Juan José, (seudónimo de David Viñas) (1954): “Una expresión, un signo”. En: Contorno, 2, Mayo. Reproducido en Carlos Magnone y Jorge Warley (eds) (1993): Contorno Selección. Buenos Aires: Centro Editor de América Latina, pp. 71-80. Gracia, Jordi (2004), La Resistencia Silenciosa. Barcelona: Anagrama.

Halperin Donghi, Tulio (1999): Vida y Muerte de la República Verdadera. Buenos Aires: Ariel. 
- (2003): La Argentina y la Tormenta del Mundo. Buenos Aires: Siglo XXI.

Hechos e Ideas. Revista Radical (Buenos Aires).

Hurtado, Leopoldo (1947): "La música en Argentina". En: Expresión, 2, enero, p. 196.

Irazusta, Julio (1975): Memorias-Historia de un historiador a la fuerza. Buenos Aires: Ediciones Culturales Argentinas.

Judt, Tony (1992): Past Imperfect-French Intellectuals 1944-1956. Berkeley, University of California Press.

King, John (1989): Sur Estudio de la revista argentina y de su papel en el desarrollo de una cultura 1931-1970. México: FCE.

La Nación (Buenos Aires).

Larra, Raúl (1982): Etcétera. Buenos Aires: Ánfora.

Liberalis (Buenos Aires).

Luna, Félix (1987): Perón y su Tiempo. Buenos Aires: Editorial Sudamericana.

Mc Gee Deutsch, Sandra/Dolkart, Ronald H. (1993): The Argentine Right. Wilmington: Scholarly Resources Books.

Mantovani, Juan (1955): “La formación del hombre libre”. En: Sur, 237, noviembrediciembre, pp. 18-23.

Mayoría (Buenos Aires).

Mundo Literario (Buenos Aires).

Nállim, Jorge (2003): "De los intereses gremiales a la lucha política: la Sociedad Argentina de Escritores (SADE), 1928-1946”. En: Prismas, 7, pp. 117-138.

Neiburg, Federico (1998): Los intelectuales y la invención del peronismo. Buenos Aires: Alianza Editorial.

Newton, Ronald (1992): The Nazi Menace in Argentina, 1931-1947. Stanford: Stanford University Press.

Oliver, María Rosa (1971): "Entrevista”, Archivo de Historia Oral, Instituto Di Tella, $\mathrm{C} 2-3$.

Olivera, Miguel Ángel Alfredo (1952), "Sección Teatro”. En: Sur, septiembre - octubre, $215-216$, p. 147.

Peralta, Carlos (1955): “La rosa negra”. En: Sur, 237, noviembre-diciembre, p.113.

Perón, Juan Domingo (1949): Perón habla a los docentes. Buenos Aires: Subsecretaría de Informaciones.

- (1950): "Hablando a los intelectuales". En: Hechos e Ideas, XI, p.77.

Pineda, Ángel (1959): “Los socios de la SADE 'benemérita institución, reducto de la inteligencia libre'-también escribían en las revistas oficiales del peronismo”. En: Mayoría, 26 de marzo, p. 24.

- "Una carta aclaratoria del escritor Delio Panizza: hechos, circunstancias y conclusiones que de la misma se extraen". En: Mayoría, 16 de abril, p. 23.

Plotkin, Mariano/González Leandri, Ricardo (2000): "El regreso a la democracia y la consolidación de las nuevas elites intelectuales. El caso de Punto de Vista: Revista de Cultura. Buenos Aires (1978-1985). En: Plotkin Mariano / González Leandri, Ricardo (edts.): Localismo y globalización. Aportes para una historia de los intelectuales en Iberoamérica. Madrid: CSIC, pp. 217-240. 
Portantiero, Juan Carlos (1961): Realismo y Realidad en la Narrativa Argentina. Buenos Aires: Procyon.

Propósitos (Buenos Aires).

Quattrocchi-Woisson, Diana (1995): Los males de la memoria. Buenos Aires: Emecé.

Realidad (Buenos Aires).

Rivera, Jorge (1980): "El auge de la industria cultural (1930-1955)". En: Historia de la Literatura Argentina, II, Buenos Aires: FCE, p. 577.

Romero Delgado, Manuel (1959): “¿Quién logró del ministro Borlenghi la libertad de los intelectuales de ASCUA: el Círculo de Prensa o el Sindicato Argentino de Escritores?". En: Mayoría, 19 de febrero de 1959, p. 96.

Sarlo, Beatriz (2003): Borges, un escritor en las orillas. Buenos Aires: Seix Barral.

Sigal, Silvia (1996): Le rôle politique des intellectuels en Amérique Latine. La derivé des intellectuels en Argentine. Paris: L' Harmattan.

Sociedad Argentina de Escritores (SADE) (1941): III Congreso de Escritores-Tucumán-Resoluciones, Declaraciones y Conferencias. Buenos Aires: SADE.

Sorrentino, Fernando (1992): Siete Conversaciones con Adolfo Bioy Casares. Buenos Aires: Editorial Sudamericana.

Sur (Buenos Aires).

Terán, Oscar (1986): En Busca de la ideología argentina. Buenos Aires: Catálogos Editora.

Torre, Juan Carlos (1990): La Vieja Guardia Sindical: sobre los origenes del peronismo. Buenos Aires: Editorial Sudamericana.

Viñas, David (1954): "La historia excluida: Ubicación de Martínez Estrada”, en: Contorno, 4, Diciembre. Reproducido en Carlos Magnone y Jorge Warley (eds) (1993): Contorno Selección. Buenos Aires: Centro Editor de América Latina, pp 30-48. Wagner de Reyna, Albert (1947): "Fin de Era". En: Realidad, 2, Marzo-Abril, pp. 229246.

Walter, Richard (1993): "The right and the Peronists, 1943-1955". En: Mc Gee Deutsch, Sandra / Dolkart, Ronald: The Argentine Right. Willimigton: Scholarly Resources Inc., pp. 99-118.

Zannatta, Loris (1999): Perón y el mito de la Nación Católica. Buenos Aires, Editorial Sudamericana. 